\title{
Thoracic Manifestations of Connective Tissue Diseases
}

\author{
Carina A. Ruano, MD, ${ }^{a}$ Rita N. Lucas, MD, ${ }^{a}$ Cecília I. Leal, MD, \\ João Lourenço, MD, ${ }^{a}$ Sofia Pinheiro, $M D,{ }^{c}$ Otília Fernandes, $M D$, \\ and Luísa Figueiredo, $M^{b}$
}

\begin{abstract}
Connective tissue diseases (CTDs) comprise several immunologic systemic disorders, each of which associated with a particular set of clinical manifestations and autoimmune profile. CTDs may cause numerous thoracic abnormalities, which vary in frequency and pattern according to the underlying disorder. The CTDs that most commonly involve the respiratory system are progressive systemic sclerosis, systemic lupus erythematosus, rheumatoid arthritis, Siögren syndrome, polymyositis, dermatomyositis, and mixed connective tissue disease. Pulmonary abnormalities in this group of patients may result from CTD-related lung disease or treatment complications, namely drug toxicity and opportunistic infections. The most important thoracic manifestations of CTDs are interstitial lung disease and pulmonary arterial hypertension, with nonspecific interstitial pneumonia being the most common pattern of interstitial lung disease. Highresolution computed tomography is a valuable tool in the initial evaluation and follow-up of patients with CTDs. As such, general knowledge of the most common high-resolution computed tomographic features of CTD-related lung disease allows the radiologist to contribute to better patient management.
\end{abstract}

\section{Introduction}

Connective tissue diseases (CTDs), also named collagen vascular diseases, are a heterogeneous group of

From the a Department of Radiology, Hospital de Santo António dos Capuchos, Central Lisbon Hospital Centre, Lisbon, Portugal; ${ }^{\mathrm{b}}$ Department of Radiology, Hospital de Santa Marta, Central Lisbon Hospital Centre, Lisbon, Portugal; and ${ }^{\mathrm{c}}$ Department of Internal Medicine, Hospital de Santo António dos Capuchos, Central Lisbon Hospital Centre, Lisbon, Portugal. Reprint requests: Carina A. Ruano, MD, Department of Radiology, Hospital de Santo António dos Capuchos, Alameda de Santo António dos Capuchos, 1169-050 Lisboa, Portugal. E-mail: carinaasr@gmail.com.

Curr Probl Diagn Radiol 2015;44:47-59.

(c) 2014 Mosby, Inc. All rights reserved.

$0363-0188 / \$ 36.00+0$

http://dx.doi.org/10.1067/j.cpradiol.2014.07.002 immunologically mediated systemic disorders, in which the thoracic organs constitute a frequent target.

Thoracic manifestations of CTDs are broad and vary according to specific disease types, frequently constituting a challenge for the radiologist. Furthermore, these patients may present opportunistic infections and drug-related complications, which should be ruled out before confirming the diagnosis of thoracic involvement in CTDs.

This article describes the thoracic high-resolution computed tomography (HRCT) findings of the most common CTDs, as well as possible complications associated with CTD treatment.

\section{General Aspects of Thoracic Manifestations of CTDs}

The most important thoracic manifestations and the major causes of morbidity and mortality in patients with CTDs are interstitial lung disease (ILD) and pulmonary arterial hypertension (PAH). ${ }^{1}$

Thoracic abnormalities usually appear simultaneously or after typical CTD systemic manifestations. However, they may also precede extrathoracic manifestations by months or years, or, occasionally, be the dominant feature of the systemic autoimmune disease. $^{1-3}$

The distinction between idiopathic ILD and CTDrelated ILD may be difficult considering thoracic HRCT imaging features alone. However, demographic features, serum antibodies, and extrapulmonary manifestations may aid the diagnosis. Patients with CTDrelated ILD are typically younger than those with idiopathic ILD and female. Pulmonary involvement in CTDs is generally multicompartmental (involving the lungs, airways, pleura, and pulmonary vascular system), and may be associated with esophageal 
abnormalities or pericardial disease. Furthermore, patients with CTDs may also present extrathoracic manifestations such as Raynaud phenomenon and articular involvement. ${ }^{4,5}$ Mediastinal lymphadenopathy is also a frequent finding in patients with CTDs and should not be considered malignant in the absence of a known neoplasm. ${ }^{1}$

\section{Patterns of ILD Associated With CTDs}

CTD-related ILD commonly displays similar morphologic patterns to those of the idiopathic counterpart. ${ }^{6}$ Thorough knowledge of idiopathic ILD patterns is vital for understanding ILD in the setting of CTDs.

The most common histopathologic patterns of ILD in patients with CTDs are nonspecific interstitial pneumonia (NSIP), usual interstitial pneumonia (UIP), organizing pneumonia (OP), and lymphoid interstitial pneumonia (LIP). NSIP is the single most frequent pattern of ILD in most CTDs, with the exception of patients with rheumatoid arthritis (RA) in which the UIP pattern predominates. ${ }^{7,8}$ The NSIP pattern is more frequently seen in association with CTDs than as an idiopathic disease. As such, an underlying CTD must be sought at diagnosis and during follow-up of patients with NSIP-like abnormalities, especially of young age and with positive autoantibodies. ${ }^{8,9}$ A recently published study, which aimed to determine the frequency of unrecognized CTDs in a cohort of patients with ILD, revealed that $15 \%$ of 114 patients with ILD were diagnosed with a new CTD as a direct consequence of their ILD evaluation. $^{10}$

\section{Nonspecific Interstitial Pneumonia}

Pathologically, the NSIP pattern is characterized by spatially and temporally homogenous lung involvement. On account of the varying degrees of interstitial inflammation and fibrosis, NSIP is divided into 2 categories: cellular and fibrotic NSIP. While interstitial inflammation is the dominant finding of cellular NSIP, interstitial fibrosis and mild inflammation are the key features of fibrotic NSIP, the latter accounting for substantially worse prognosis. . $^{6,11}$

Typical HRCT findings of NSIP include patchy ground-glass opacities and reticular abnormalities (Fig 1). In advanced stages, mild traction bronchiectasis and bronchiolectasis can be seen. Subpleural cysts may rarely be seen in fibrotic NSIP; however, these are usually smaller and limited in extent when

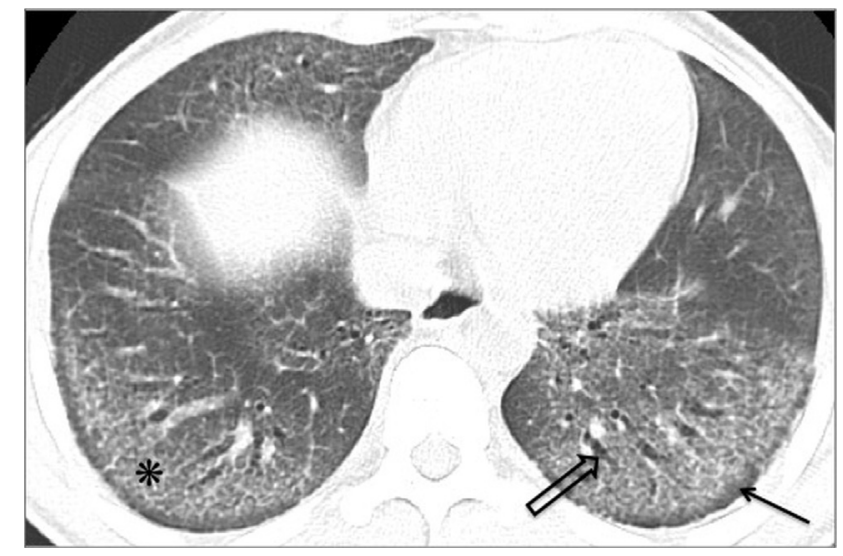

FIG 1. NSIP pattern. HRCT image of the lower lobes shows peripheral reticular abnormalities and ground-glass opacities (*), with mild traction bronchiectasis (open arrow). The subpleural lung is spared (arrow).

compared with those of UIP. Patients with NSIP typically demonstrate bilateral disease with lower lobe predominance, and peripheral or peribronchovascular distribution. A unique HRCT feature of NSIP that reinforces its diagnosis is the relative sparing of the lung parenchyma immediately adjacent to the pleura (subpleural sparing). ${ }^{1,6}$

\section{Usual Interstitial Pneumonia}

The UIP pattern is characterized by histopathologic and radiological heterogeneous lung involvement, with areas of fibrosis (with scarring and honeycombing) alternating with areas of normal lung. According to the American Thoracic Society-European Respiratory Society-Japanese Respiratory Society-Latin American Thoracic Association Idiopathic Pulmonary Fibrosis 2011 guidelines, the typical HRCT pattern of UIP includes reticular opacities with honeycombing with subpleural and basal predominance, with or without traction bronchiectasis, without features to suggest an alternative diagnosis (Fig 2). ${ }^{12}$ When present, ground-glass opacities in UIP are usually less extensive than those observed in NSIP and should be regarded as early fibrosis instead of inflammatory changes. ${ }^{13}$

The differentiation between UIP and NSIP has important therapeutic and prognostic implications, with NSIP showing better response to corticosteroid therapy and a better prognosis. However, there is considerable overlap in the HRCT patterns, and the diagnosis may not be straightforward. Several imaging clues may help the radiologist in this evaluation 


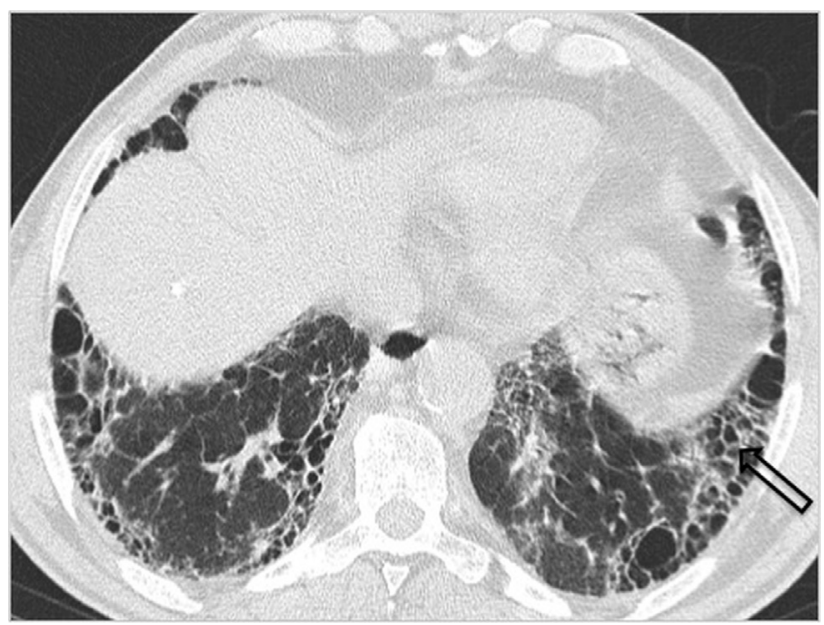

FIG 2. UIP pattern. HRCT image of the lower lobes shows reticular opacities and subpleural honeycombing (open arrow).

(Table 1), with honeycombing being the dominant imaging feature of UIP and ground-glass opacities the key finding of NSIP. ${ }^{14}$

\section{Organizing Pneumonia}

OP is a clinicoradiological syndrome characterized by unilateral or bilateral patchy consolidations, with lower lobe predominance, peripheral or peribronchial distribution, with possible sparing of the subpleural lung. These opacities may change their location and size even without treatment, constituting a clue for the diagnosis. ${ }^{6}$ Perilobular opacities are a distinctive finding, frequently observed in patients with OP, resulting from involvement of the structures that border the secondary lobule. They appear as illdefined, bowed or polygonal opacities, predominantly in the subpleural regions. When present, this perilobular pattern may support the diagnosis of OP. ${ }^{15}$ Another highly suggestive feature of OP is the reverse halo sign ("atoll" sign), which consists of a rounded area of ground-glass opacity surrounded by a ring of consolidation (Fig 3). Other findings may include ground-glass opacities, air bronchogram and bronchial dilatation within the areas of consolidation, tree-in-

TABLE 1. Key HRCT features for the differentiation between NSIP and UIP

\begin{tabular}{|c|c|c|}
\hline HRCT features & NSIP & UIP \\
\hline Predominant findings & Ground-glass opacities & Honeycombing \\
\hline Distribution & $\begin{array}{l}\text { Basal and peripheral } \\
\text { Subpleural sparing } \\
\text { Peribronchovascular }\end{array}$ & $\begin{array}{l}\text { Basal and peripheral } \\
\text { Subpleural }\end{array}$ \\
\hline
\end{tabular}

bud pattern, and nodular opacities. Histologically, OP is characterized by granulation tissue polyps in the airspaces and distal airways, with preservation of lung architecture and volume. ${ }^{6,9,16}$

\section{Lymphoid Interstitial Pneumonia}

LIP is an uncommon entity, most frequently seen in the setting of systemic diseases (namely Sjögren syndrome [SS] and acquired immunodeficiency), being extremely rare as an idiopathic disease. It is histologically characterized by diffuse infiltration of the interstitium by polyclonal lymphocytes, plasma cells, and histiocytes. ${ }^{17}$ The radiological hallmarks of LIP are bilateral, either diffuse or lower lobe, groundglass opacities, and thin-walled perivascular cysts (Fig 4). ${ }^{6,9}$ These cysts are centrally located in the lung parenchyma and are thought to result from partial


FIG 3. OP pattern. HRCT images from the same patient $(2$ months apart; A and B) show migrating areas of ground-glass opacity (*) surrounded by a rim of consolidation (arrow) -"atoll" sign. 


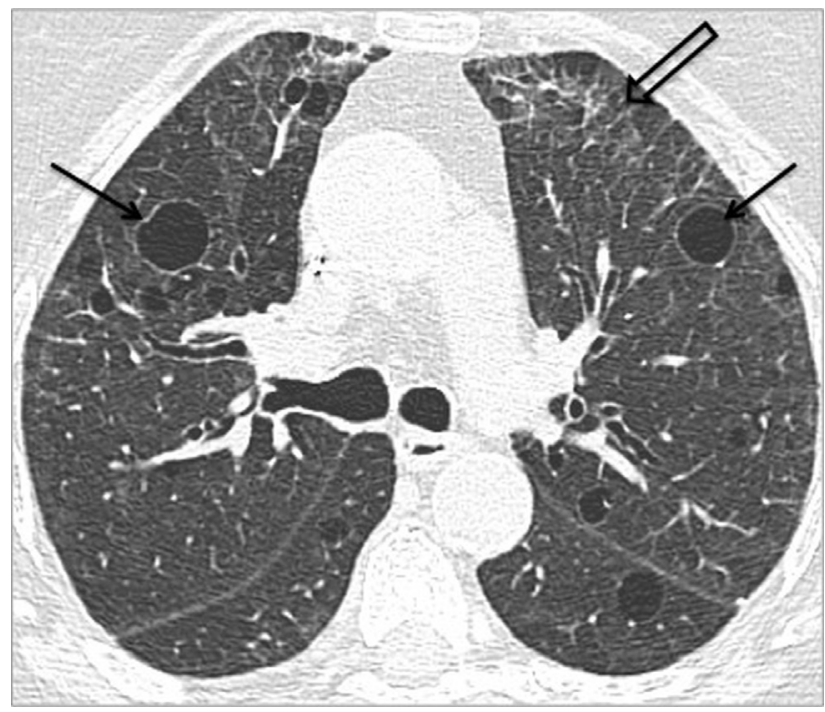

FIG 4. LIP pattern. HRCT image shows subtle ground-glass opacities, reticular abnormalities (open arrow), and thin-walled perivascular cysts (arrows).

obstruction of bronchioles by the lymphocytic infiltrate. Other features may include centrilobular nodules and interlobular septal thickening. ${ }^{18}$

\section{Pulmonary Arterial Hypertension}

$\mathrm{PAH}$ is defined as a mean resting pulmonary artery pressure $\geq 25 \mathrm{~mm} \mathrm{Hg}$, with pulmonary capillary wedge pressure $\leq 15 \mathrm{~mm} \mathrm{Hg} .{ }^{19} \mathrm{PAH}$ is commonly associated with CTD, most frequently with progressive systemic sclerosis ( $\mathrm{SSc}$ ) (particularly with the limited form), and may or may not be associated with ILD. HRCT signs of PAH include dilatation of the pulmonary arterial trunk $(\geq 2.9 \mathrm{~cm}$, evaluated on axial images at the level of its bifurcation, perpendicular to its long axis) and of the main pulmonary arteries and their segments, enlargement of the right heart chambers and of the azygos-hemiazygos venous system, and contrast reflux into the inferior vena cava and hepatic veins. ${ }^{1,20}$

\section{Specific CTDs}

\section{Progressive Systemic Sclerosis}

Progressive SSc, also known as scleroderma, is a multisystemic autoimmune disorder characterized by overproduction of collagen, leading to fibrosis of the skin, lungs, and visceral organs, and small vessel vasculopathy. ${ }^{21} \mathrm{SSc}$ can be classified into 2 major forms: diffuse SSc and limited SSc (the latter previously known as CREST syndrome, characterized by calcinosis, Raynaud phenomenon, esophageal dysmotility, sclerodactyly, and telangiectasis), each subgroup associated with different clinical manifestations, autoimmune profile, and prognosis. ${ }^{22}$ SSc has female predilection (3-8 females:1 male), with peak frequency between 45 and 64 years of age. ${ }^{1}$

ILD and PAH are common in the course of SSc and are the leading causes of disease-related morbidity and mortality, with PAH being the single most important cause of death. While pulmonary fibrosis typically affects patients with diffuse SSc, PAH is especially prevalent in patients with the limited form of the disease. ${ }^{23}$

ILD is said to be present in $75 \%$ of patients at autopsy, being more common and more severe in SSc than in any other CTD. However, patients with interstitial pathology may be asymptomatic in early stages. ${ }^{5,23}$ The HRCT findings at presentation may have prognostic significance: patients with extensive ILD at baseline evaluation (affecting $\geq 20 \%$ of the lung) show higher mortality rate and rapid decline of lung function, whereas patients with less extensive $(<20 \%)$ or no lung involvement at initial HRCT evaluation appear to have good long-term prognosis. ${ }^{4,24}$

NSIP is the most common pattern of ILD in patients with SSc (Figs 5 and 6), with HRCT features closely resembling those of idiopathic NSIP. ${ }^{23,25}$ UIP is the second most common pattern of ILD, generally accounting for a worse prognosis than NSIP. ${ }^{1,2}$ Ground-glass opacities should not be interpreted as areas of inflammation unless reversible after therapy (Fig 7), as most ground-glass opacities represent early fibrotic changes. The diagnosis is further corroborated by the identification of bronchiectasis amid the ground-glass abnormalities. ${ }^{4}$

Other possible pulmonary manifestations of SSc include OP, alveolar hemorrhage, bronchiectasis or bronchiolectasis (Fig 5), and respiratory muscle dysfunction. $^{23}$

As systemic manifestations may appear after a few or after several years following the diagnosis of ILD, a close follow-up of these patients is required. Extrapulmonary findings that may suggest the diagnosis of $\mathrm{SSc}$ are enlargement of the pulmonary arterial trunk and right heart chambers (signs of PAH) as well as esophageal dilatation (Fig 8). Esophageal involvement is an early manifestation of SSc, described in up to $97 \%$ of patients. It may lead to aspiration pneumonitis or bronchiolitis. ${ }^{4,26}$ The heart is also a frequent target of scleroderma, with possible involvement including myocardial fibrosis, arrhythmias, pericardial disease, and heart failure. ${ }^{26,27}$ Mediastinal lymphadenopathy is 


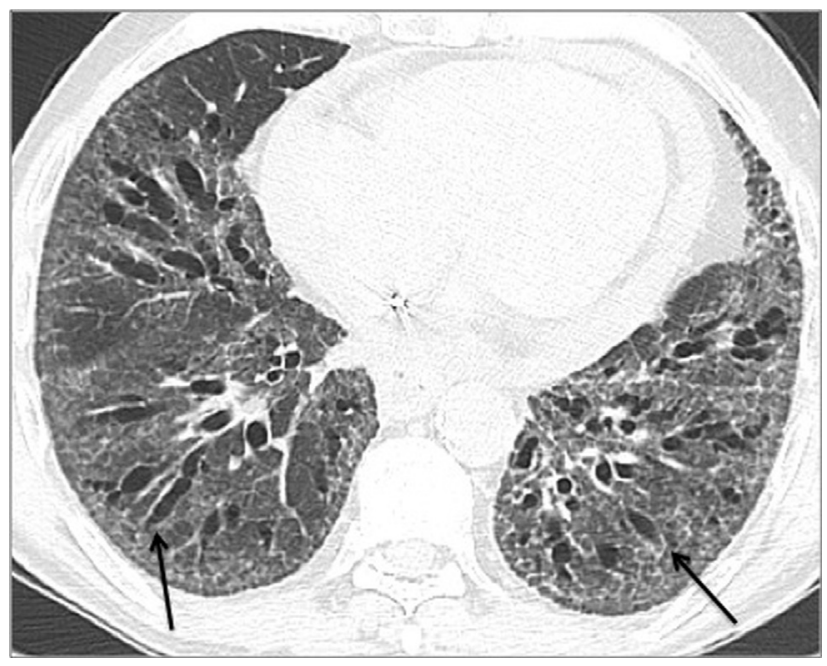

FIG 5. NSIP-like abnormalities and bronchiectasis (arrows) in a 55-year-old man with scleroderma.

likewise common, occurring in up to $50 \%$ of patients. $^{27}$ Unlike pericardial disease, pleural disease is uncommon and when present is generally accompanied by parenchymal lung disease. ${ }^{21}$

Patients with SSc show increased prevalence of malignancies compared with the general population, namely lung cancer and breast cancer. Nonetheless, the mechanism for this increased carcinogenesis remains unknown. ${ }^{1}$

\section{Systemic Lupus Erythematosus}

Systemic lupus erythematosus (SLE) is a complex autoimmune disease with a broad spectrum of

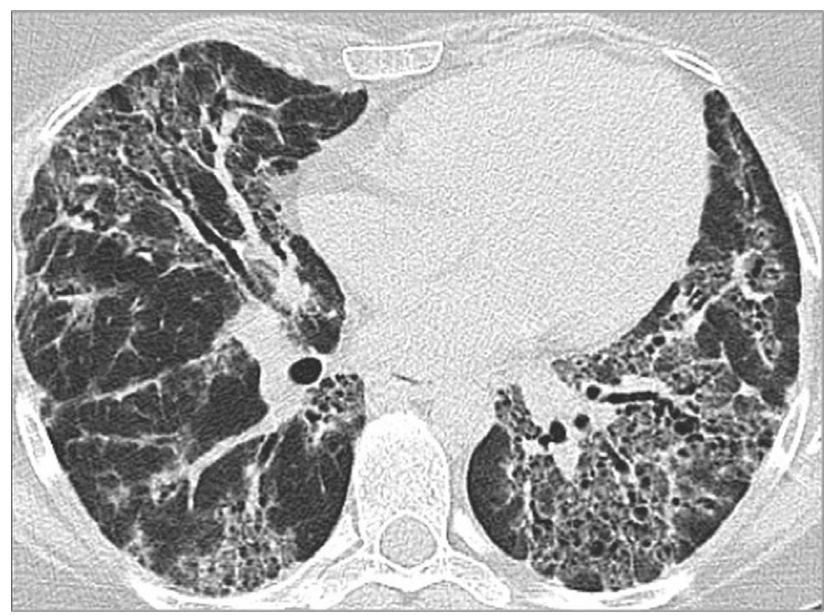

FIG 6. Fibrotic NSIP in a 28-year-old woman with scleroderma. Fibrotic NSIP can resemble UIP; however, unlike the latter, NSIP may show peribronchovascular predominance of reticulation, relative sparing of the subpleural lung, or both. immunologic and clinical manifestations. SLE affects primarily women (6-9 females: 1 male), occurs predominantly in childbearing age, and has an African American predilection., 27

The most frequent thoracic manifestation of SLE is pleural disease. Pleuritic pain is said to be present in $45 \%-60 \%$ of patients, and pleural effusions (unilateral or bilateral) have been reported in $30 \%-50 \%$ of patients with SLE. ${ }^{28}$ Pericardial effusion and cardiomegaly may be present in up to $35 \%$ of patients (Fig 9). ${ }^{27}$

Acute pulmonary disease in patients with SLE presenting patchy consolidation in HRCT images may represent pneumonia, acute lupus pneumonitis, alveolar hemorrhage, or pulmonary edema. ${ }^{27}$ Pneumonia is the leading cause of lung infiltrates and a frequent cause of morbidity and mortality in this
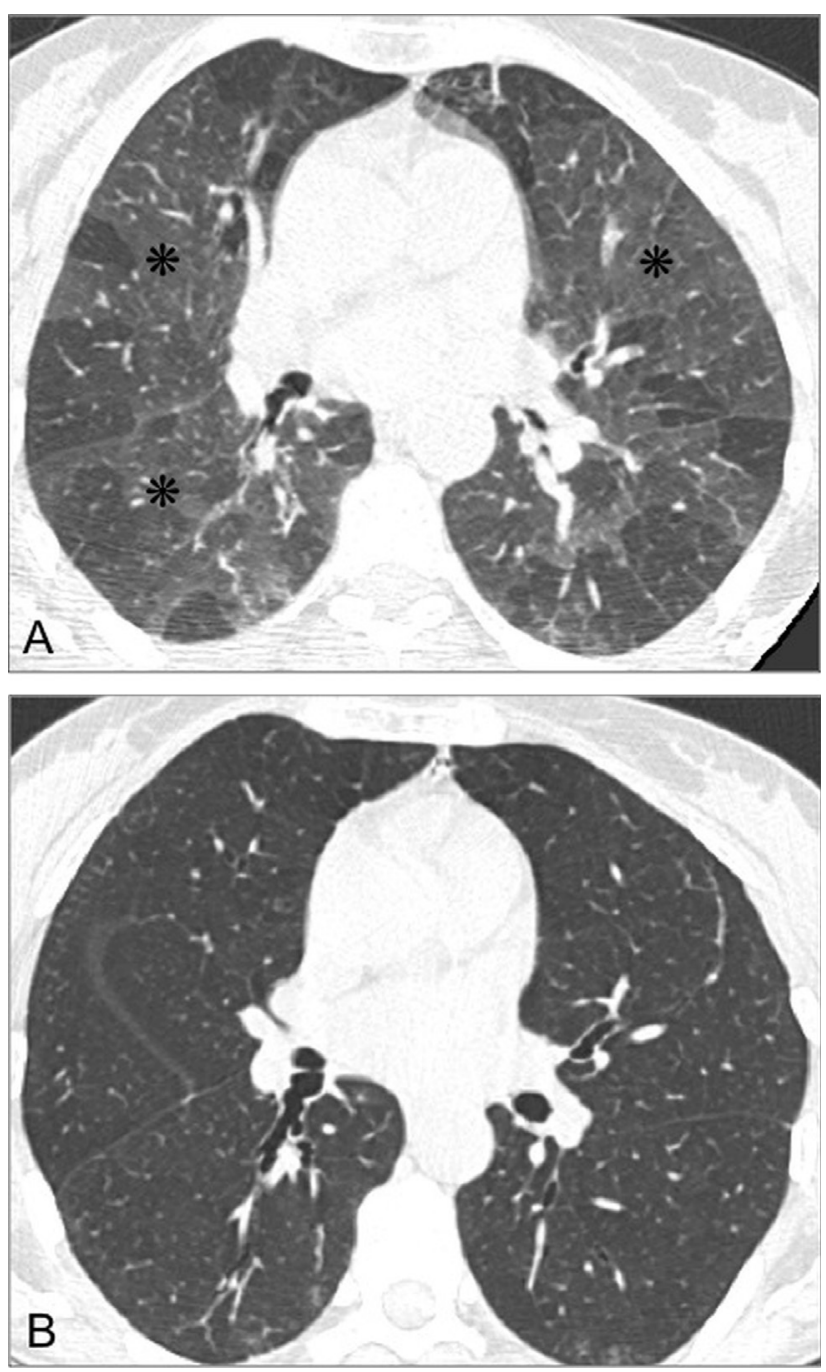

FIG 7. Geographic pattern of ground-glass opacities $(*$ in $(A))$, reversible after treatment with cyclophosphamide (B), in a 57-yearold woman with scleroderma. 

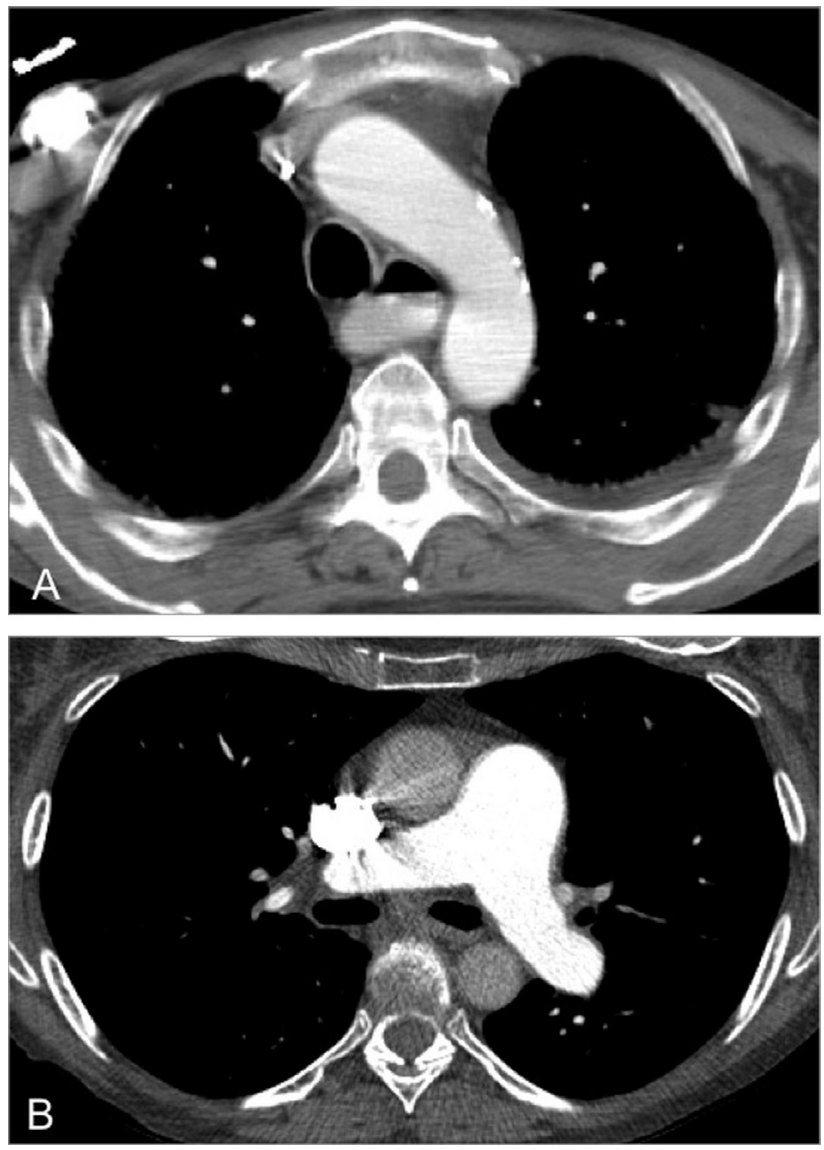

FIG 8. Extrapulmonary findings in SSc: (A) esophageal dilatation with air-fluid level in a 55-year-old man and (B) enlargement of the main pulmonary artery in a 62-year-old woman.

group of patients, accounting for $57 \%$ of all fatal infections. ${ }^{29}$ Although the most common pulmonary infection is community-acquired pneumonia, atypical

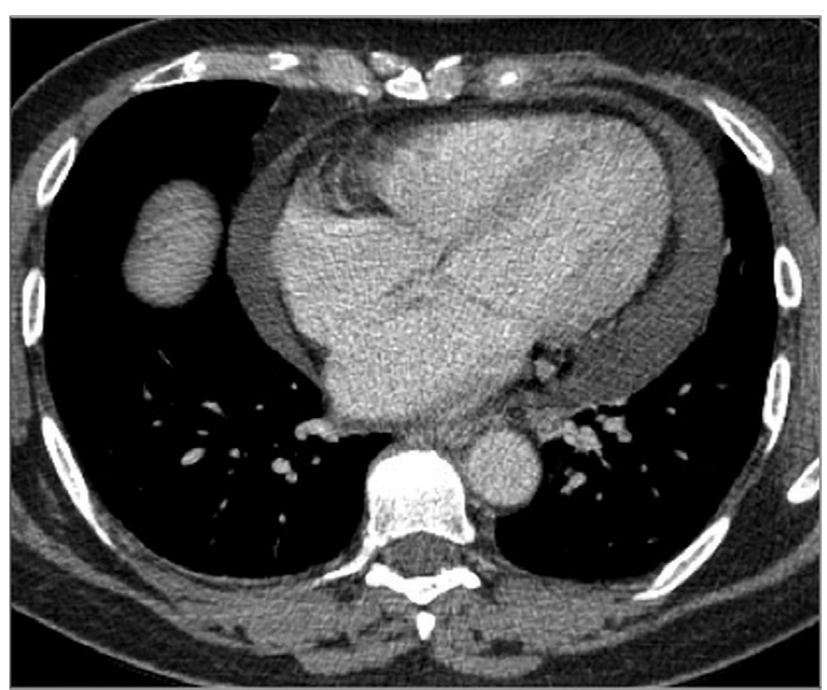

FIG 9. Pericardial effusion in a 53-year-old woman with SLE. microorganisms should also be considered, particularly in the setting of immunosuppressive therapy. ${ }^{1}$ Acute lupus pneumonitis is thought to occur in $2 \%$ $10 \%$ of patients with SLE and may be the presenting manifestation of the disease in half of these patients. As the clinical presentation of this entity may be similar to that of infectious pneumonia (cough, dyspnea, and fever), infectious diseases must be meticulously ruled out before considering the diagnosis of lupus pneumonitis and initiating immunosuppressive therapy. Diffuse alveolar hemorrhage may mimic acute lupus pneumonitis, both clinically and radiologically. However, the presence of hemoptysis and decrease in hematocrit level, associated with diffuse alveolar infiltrates, should suggest the correct diagnosis (Fig 10). ${ }^{29}$ This diagnosis can be further validated by bronchoscopy with sequential bronchoalveolar lavages. ${ }^{2}$

Chronic lung disease in patients with SLE includes "shrinking lung" syndrome and pulmonary fibrosis. "Shrinking lung" syndrome is an uncommon disorder of unknown pathogenesis characterized by chest pain and dyspnea with diaphragmatic elevation and abnormal respiratory function tests, without evidence of parenchymal or pleural disease. ${ }^{30}$ Unlike in most CTDs, ILD (presenting as NSIP or UIP) is a rare respiratory manifestation in SLE (3\%). Clinically important airways disease is likewise infrequent; however, bronchiectasis may be seen in HRCT studies. ${ }^{1,2}$ PAH is also an uncommon manifestation of SLE (6\%), being frequently associated with pulmonary thromboembolic disease or interstitial fibrosis.



FIG 10. Diffuse alveolar hemorrhage in a 20-year-old woman with SLE. The diagnosis was suspected by the presence of hemoptysis, low hematocrit level, and extensive alveolar opacities in HRCT scan, and confirmed with bronchoscopy showing hemorrhagic bronchoalveolar lavage. 
The pathophysiology of PAH in SLE is multifactorial and incompletely understood. It may encompass pulmonary vasculopathy, chronic thromboembolic disease (related to antiphospholipid antibody syndrome), left heart disease, lung disease, or the combination of these factors. ${ }^{31}$

Patients with SLE have increased risk of malignancy compared with the general population, with lung cancer and lymphoma being the most common associations. ${ }^{1,5}$

\section{Rheumatoid Arthritis}

$\mathrm{RA}$ is the most common CTD, characterized by symmetric polyarthritis, leading to progressive joint damage. RA affects approximately $1 \%$ of the population, usually presenting in patients between 20 and 50 years of age and, as the majority of CTDs, has female predominance (3 females: 1 male). Conversely, pleuropulmonary involvement, which accounts for $20 \%$ of all RA-related deaths, is more frequent in the male sex. ${ }^{32}$

The most common thoracic manifestation of RA is pleural disease. It may be present in up to $50 \%$ of patients and consists on pleural effusions, pleural thickening, or pneumothorax. Pleural effusions are typically unilateral, may be loculated, and are more frequently seen in patients with long-standing active articular disease and rheumatoid nodules. Chronic effusions may lead to pleural thickening, causing reduced lung expansion despite adequate drainage (trapped lung). ${ }^{28,32}$

ILD is also a chief thoracic manifestation of RA and may present several histopathologic and HRCT patterns, with the most common patterns being UIP, NSIP, OP, and LIP. Unlike patients with other CTDs, in which the NSIP pattern predominates, patients with RA most commonly present UIP-like abnormalities (Fig 11). ${ }^{1}$ This entails prognostic implications, as RArelated UIP has considerably worse prognosis than NSIP. ${ }^{32,33}$ As with idiopathic UIP, honeycombing in RA predominates in the posterior subpleural lower lobes. However, anterior upper lobe honeycombing may also be present in RA-related UIP. ${ }^{34}$ Similarly to other entities presenting lung fibrosis, patients with RA have higher risk of developing lung cancer. ${ }^{21}$

Pulmonary (necrobiotic) rheumatoid nodules are characteristically well defined, have a maximum diameter of 0.5-5.0 cm, display peripheral distribution in the upper and middle lung regions, and may undergo cavitation in up to $50 \%$ of cases (Fig 12). Patients are typically asymptomatic unless a cavitating
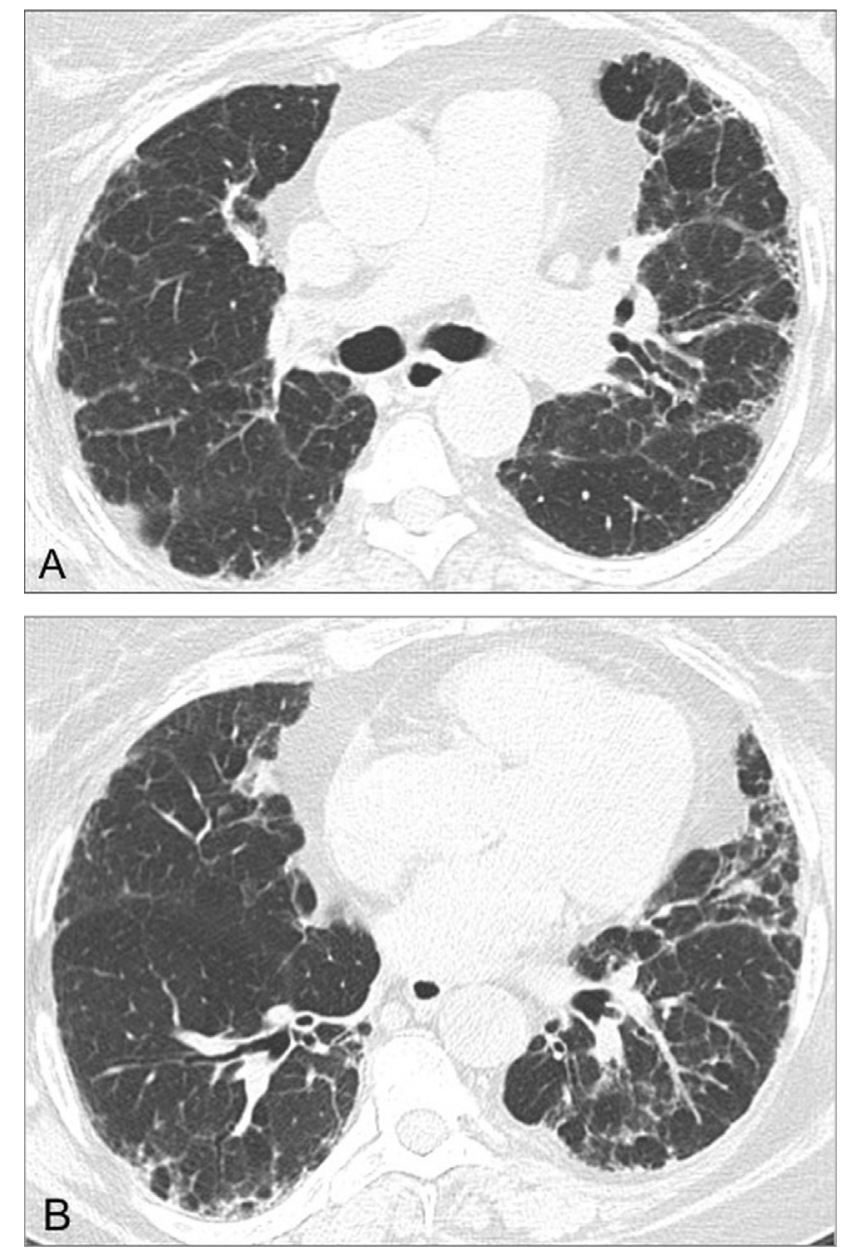

FIG 11. UIP-like fibrosis in a 72-year-old woman with RA. (A) and (B) represent different levels of the same HRCT scan.

nodule ruptures into the pleural space, leading to pneumothorax, hydropneumothorax, or empyema. Caplan syndrome refers to the association of rheumatoid nodules with pneumoconiosis (usually in coal workers' pneumoconiosis). ${ }^{35}$

Patients with RA frequently show airways disease, both of the upper and the lower airways. Cricoarytenoid arthritis, presenting with odynophagia, dysphagia, hoarseness, and globus, is a frequently overlooked condition that can lead to life-threatening airway compromise. Bronchiectasis may be seen in up to $58 \%$ of patients. Despite most patients being asymptomatic, the presence of bronchiectasis should always be highlighted, as there may be an additional risk factor for the development of mycobacterial infection, particularly in patients treated with tumor necrosis factor $\alpha(\mathrm{TNF} \alpha)$ antagonists. ${ }^{2}$ Other possible airway manifestations are constrictive (obliterative) bronchiolitis and follicular bronchiolitis. Obliterative bronchiolitis, characterized by luminal narrowing and 

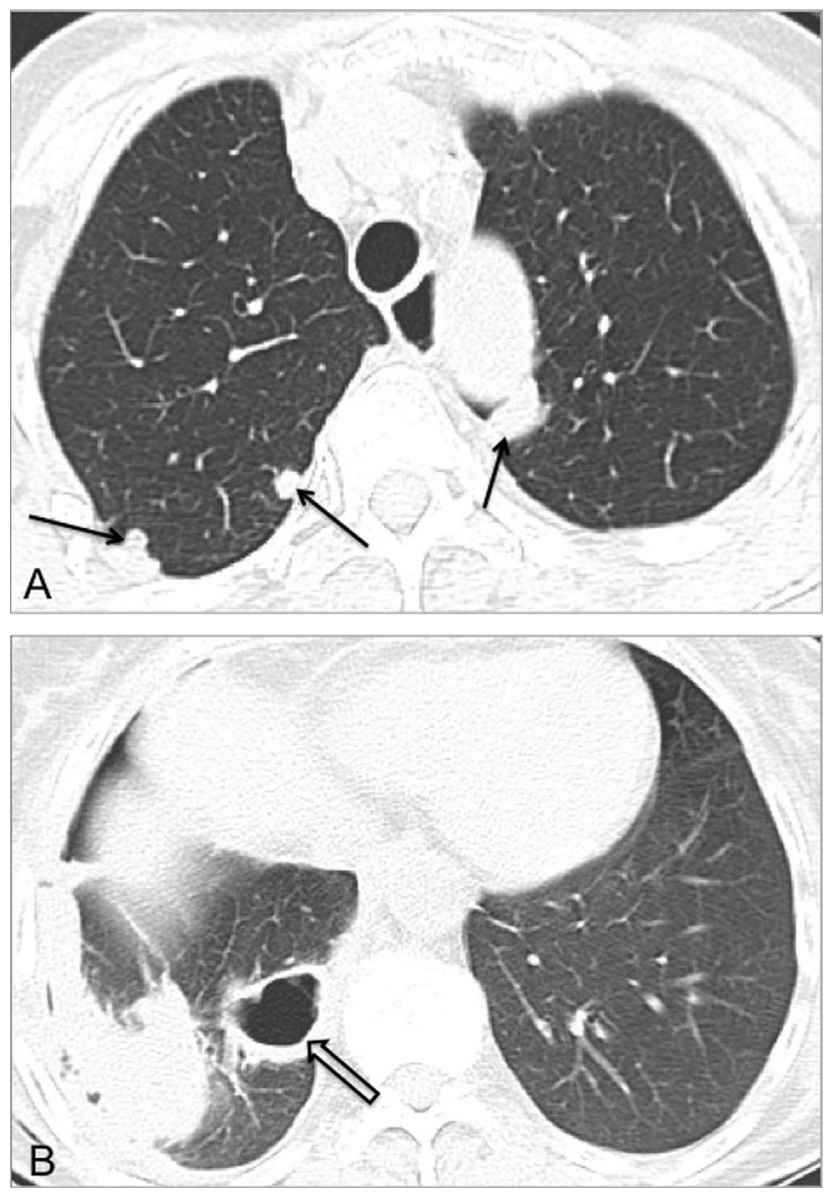

FIG 12. Rheumatoid nodules in a 77-year-old woman with RA. HRCT images show well-defined peripheral nodules in the upper lobes (arrows in (A)), and a cavitary nodule in the right lower lobe lopen arrow in (B)).

obliteration of the small airways, is regarded in HRCT studies as mosaic attenuation pattern, with areas of air trapping demonstrated on expiratory images (Fig 13). Follicular bronchiolitis, considered as the bronchocentric counterpart of LIP, is an infrequent manifestation of RA, presenting on HRCT images as small centrilobular nodules, often of ground-glass attenuation. Unlike follicular bronchiolitis, which frequently responds to corticosteroid therapy, obliterative bronchiolitis usually has poor treatment response and may lead to respiratory failure. ${ }^{1,2}$

PAH may be present in approximately $20 \%$ of patients with RA and is usually associated with pulmonary involvement. ${ }^{32}$

\section{Siögren Syndrome}

SS is a chronic autoimmune condition characterized by lymphocytic infiltration (T lymphocytes) of various organs, most commonly of the lacrimal and salivary glands, resulting in keratoconjunctivitis sicca and xerostomia (sicca syndrome). This syndrome may occur alone or, in approximately one-third of patients, in association with other autoimmune disorders (RA, SLE, or scleroderma), termed primary and secondary SS, respectively. ${ }^{1,5}$ SS predominantly affects women (9-13 females:1 male) in the fourth and fifth decades of life, with the secondary form being more frequent than the primary counterpart (estimated prevalence of $0.5 \%-1 \%$ in primary SS and up to $30 \%$ in secondary SS)., ${ }^{2,4,21}$

Prevalence of lung involvement is SS varies widely (9\%-75\%) according to the diagnostic modalities and studied population. ${ }^{36}$ The most frequent pulmonary manifestations of SS are ILD and airways disease. ${ }^{2}$ The most common ILD pattern identified in patients with SS is NSIP, with other frequent patterns being OP, UIP, and LIP. ${ }^{37}$ Patients with primary SS have
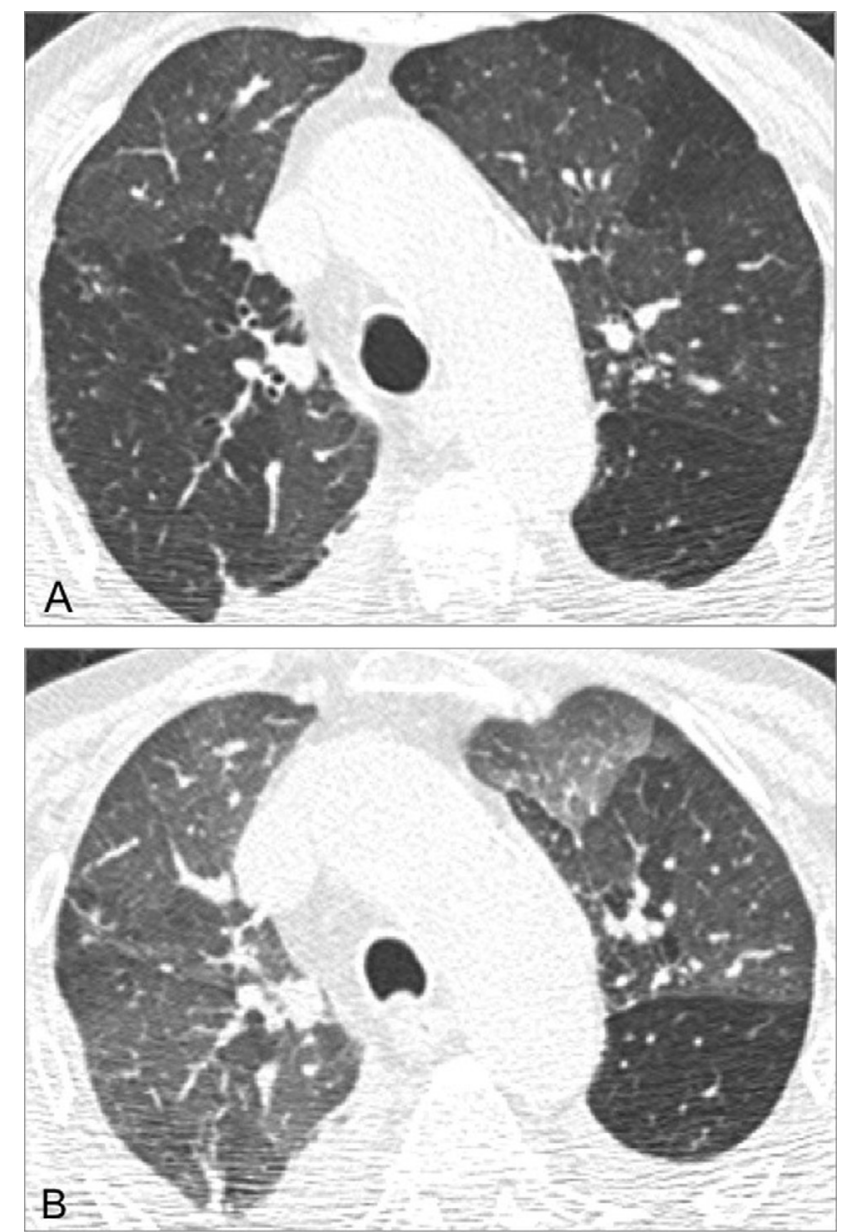

FIG 13. Constrictive bronchiolitis in an 84-year-old woman with RA. HRCT inspiratory image $(A)$ shows areas of decreased lung attenuation, which become more conspicuous on expiratory image (B), owing to air trapping. 
higher prevalence of airway abnormalities owing to disease involvement of the mucosal glands of the airways, leading to impaired microbial clearance and culminating in recurrent infections and bronchiectasis (Fig 14). ${ }^{4,36}$ Additional airway abnormalities include tracheobronchial sicca, follicular bronchiolitis, and constrictive bronchiolitis. ${ }^{38}$ Pleural disease is uncommon and almost exclusive to secondary SS, occurring most frequently in association with RA and SLE. ${ }^{1}$

Patients with SS have increased risk for lymphoma (non-Hodgkin B-cell type, arising from the salivary glands, stomach, or lung), estimated to be 16-44 times greater than in the general population. ${ }^{1,2}$ This entity should be considered whenever consolidation, pulmonary nodules, pleural effusion, or lymphadenopathy are identified in this group of patients (Fig 15). ${ }^{2,21}$

\section{Polymyositis and Dermatomyositis}

Polymyositis (PM) and dermatomyositis (DM) are idiopathic inflammatory myopathies characterized by proximal muscle weakness. PM and DM have similar signs and symptoms, with the exception that patients with DM present characteristic skin manifestations, specifically heliotrope rash and Gottron papules. ${ }^{4}$ Both entities present female predominance and bimodal incidence pattern during childhood (10-15 years) and middle adulthood (35-65 years). ${ }^{2}$ Latter onset of the disease may signal an underlying malignancy, such as lung, breast, cervix, or colon cancer. ${ }^{5}$

More than $50 \%$ of patients present thoracic manifestations, which may take 1 or more of the following forms: (1) ILD; (2) aspiration pneumonia, as a result of pharyngeal muscle weakness; and (3) direct involvement of the respiratory muscles leading to hypoventilation and respiratory failure. ${ }^{2,7}$

ILD is a frequent pulmonary manifestation and a common cause of morbidity and mortality in PM-DM. ${ }^{39}$ The most common patterns of ILD are NSIP (Fig 16), UIP, OP, and diffuse alveolar damage. ${ }^{1,40}$ NSIP and OP patterns may coexist in HRCT studies and lung biopsy specimens. ${ }^{40,41}$ As with other CTD, ILD may precede the onset of symptomatic myopathy and skin lesions. ${ }^{3,40}$ Approximately $75 \%$ of patients with PM and DM may present cardiovascular involvement, with up to $45 \%$ of patients developing congestive heart failure. ${ }^{4}$ Airway abnormalities, pleural disease, and PAH are uncommon thoracic manifestations in this group of patients. ${ }^{2}$

\section{Mixed Connective Tissue Disease}

Patients with mixed connective tissue disease (MCTD) exhibit a set of features that are characteristic of SLE, SSc, RA, and PM-DM, in addition to positive antiribonucleoprotein antibodies. MCTD affects mostly women ( 9 females: 1 male), with peak incidence in the second and third decades of life.

Clinical and radiological thoracic involvement is frequent (20\%-80\% of patients) and follows that of SLE, SSc, RA, or PM-DM. ${ }^{7}$ As such, the most important pulmonary manifestations are ILD and $\mathrm{PAH}^{42}$ ILD is the single most common pulmonary manifestation in MCTD (21\%-66\%), being NSIP the
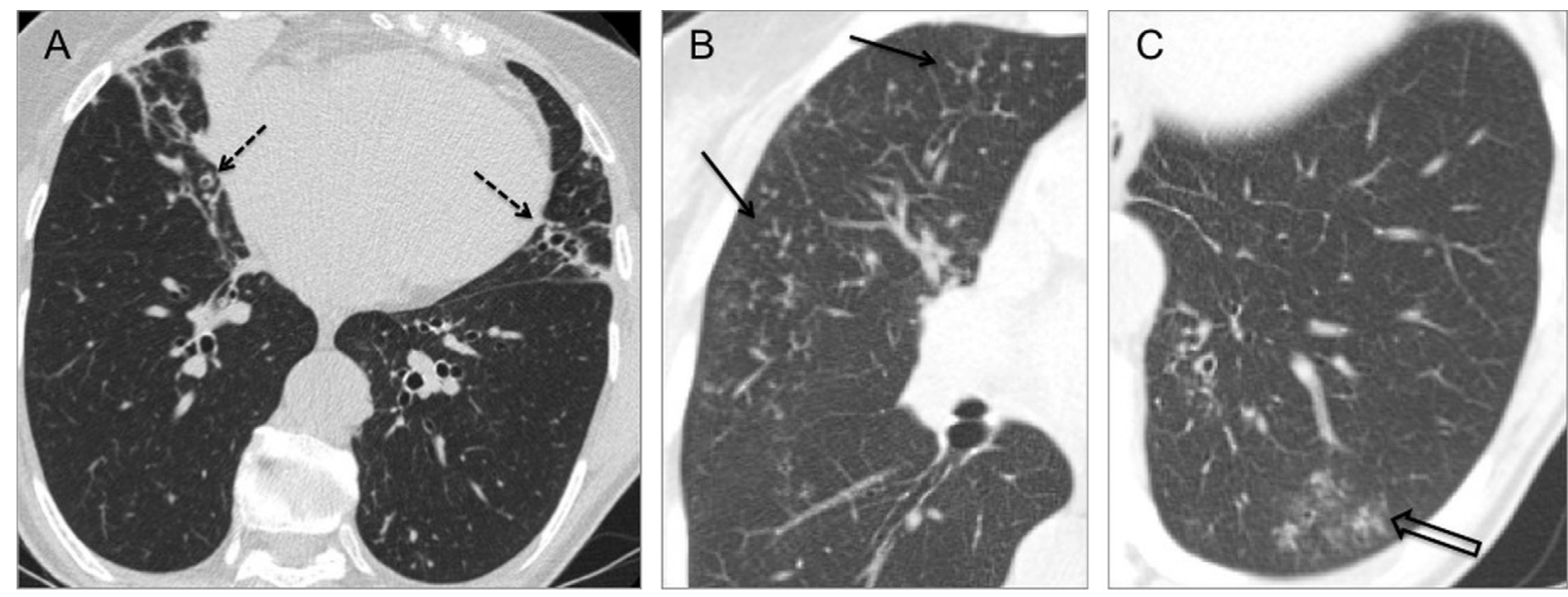

FIG 14. Bronchiectasis with bronchial wall thickening (dashed arrows in $(A)$ ) and bronchiolitis pattern (arrows showing tree-in-bud sign in (B); open arrow indicating ill-defined centrilobular nodules in (C)) in a 72-year-old woman with SS. 

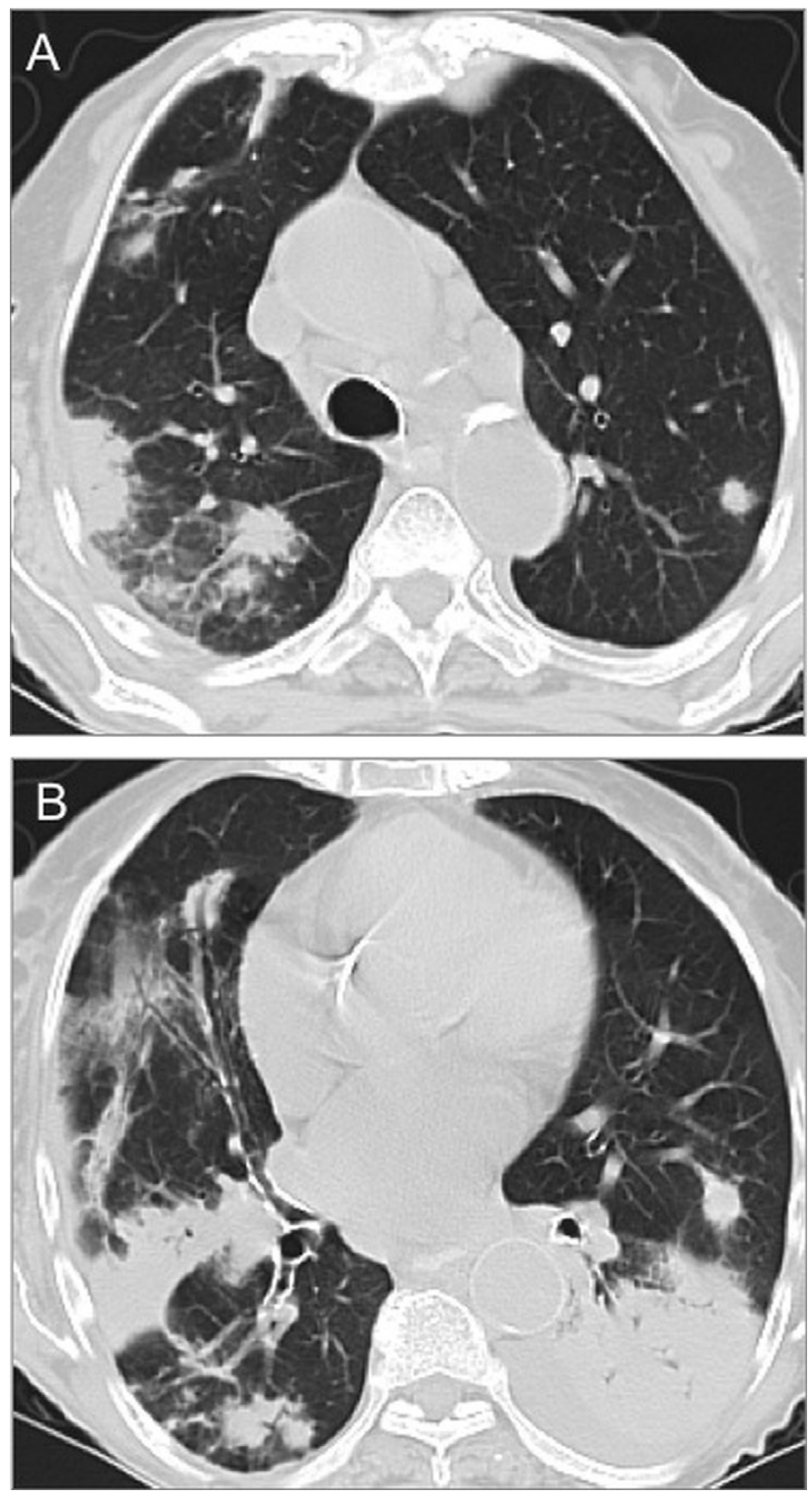

FIG 15. B-cell non-Hodgkin's lymphoma. This diagnosis should be considered in a patient with SS when areas of consolidation, large nodules, pleural effusion, or lymphadenopathy are seen.

most common histopathologic and radiographic pattern. Other possible patterns include UIP and LIP. ${ }^{4}$ Esophageal involvement is also frequent and may be responsible for chronic gastroesophageal reflux, aspiration pneumonitis, and recurrent pulmonary infections. Pleural and pericardial diseases occur in approximately $10 \%$ of patients, being more prevalent in those in which SLE features predominate..$^{5}$ Other thoracic features consist of respiratory muscle weakness, pulmonary vasculitis, alveolar hemorrhage, pulmonary thromboembolism, and mediastinal lymphadenopathy. ${ }^{23}$

\section{Drug Toxicity}

Several drugs used to treat patients with CTDs have been associated with drug-induced lung injury (Table 2), which may involve the lung parenchyma, airways, pleura, mediastinum, pulmonary vasculature, and neuromuscular system. Drug-induced ILD (DIILD) is the most common form of injury, yet it is mainly a diagnosis of exclusion. The diagnosis of DIILD requires the following: (1) detailed history of drug exposure; (2) clinical, radiological, and histopathologic patterns consistent with previous observations with the same drug; (3) exclusion of other possible causes; (4) improvement after drug removal; and (5) recurrence of identical symptoms after drug reintroduction. When timely diagnosed, DI-ILD may
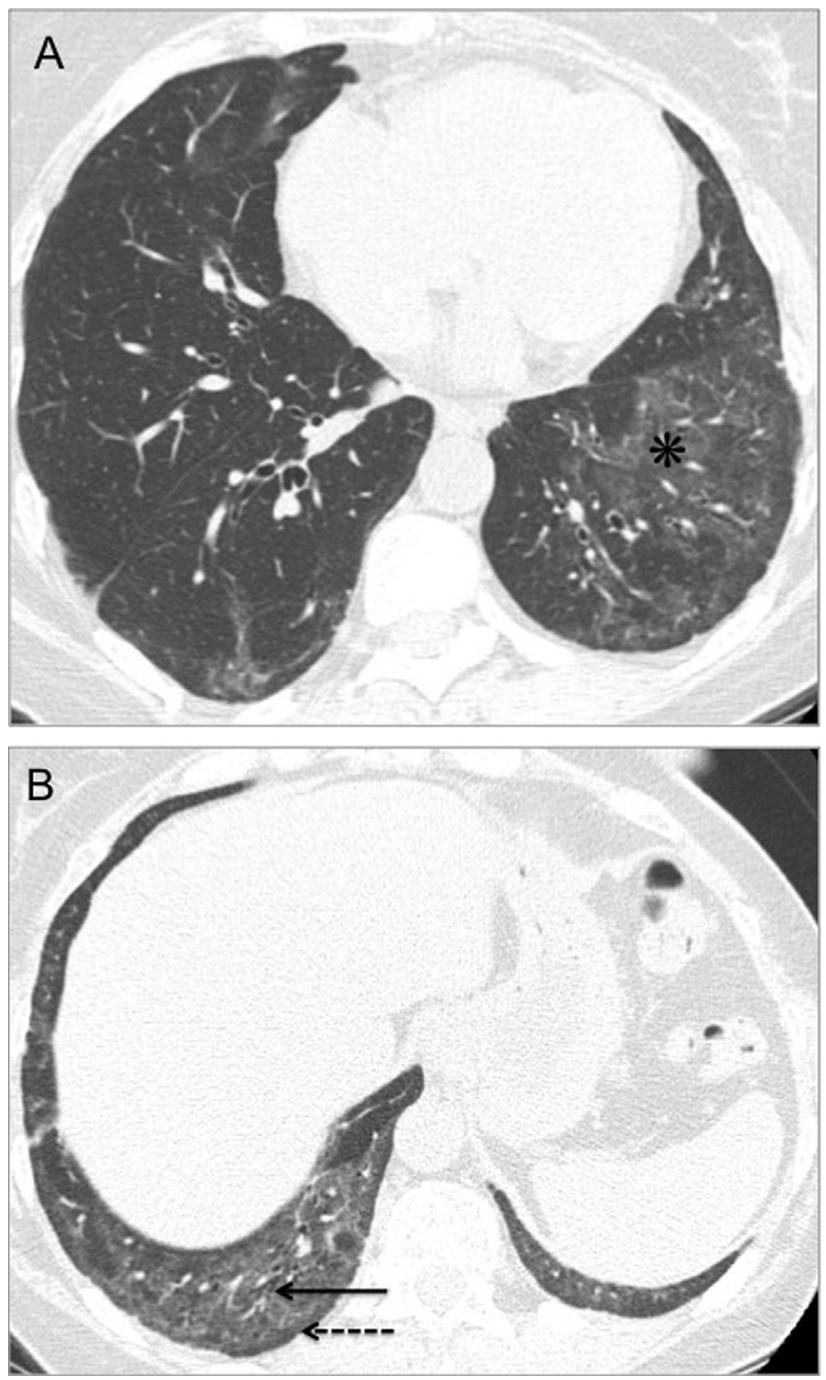

FIG 16. NSIP-like abnormalities in a 52-year-old woman with PM. HRCT images show ground-glass opacities (* in (A)) and bronchiolectasis (arrow in (B)). The subpleural lung is spared (dashed arrow in (B)). 
TABLE 2. Main patterns of drug-induced lung injury

\begin{tabular}{|c|c|}
\hline Condition & Drug \\
\hline $\begin{array}{l}\text { Interstitial pneumonia } \\
\text { (NSIP-UIP) }\end{array}$ & $\begin{array}{l}\text { Adalimumab, azathioprine, cyclophosphamide, } \\
\text { etanercept, gold salts, infliximab, } \\
\text { methotrexate, penicillamine, and sulfasalazine }\end{array}$ \\
\hline $\begin{array}{l}\text { Diffuse alveolar } \\
\text { damage }\end{array}$ & Cyclophosphamide and gold salts \\
\hline $\begin{array}{l}\text { Hypersensitivity } \\
\text { reaction }\end{array}$ & $\begin{array}{l}\text { Azathioprine, methotrexate, cyclophosphamide, } \\
\text { and sulfasalazine }\end{array}$ \\
\hline $\begin{array}{l}\text { Organizing } \\
\text { pneumonia }\end{array}$ & $\begin{array}{l}\text { Cyclophosphamide, gold salts, methotrexate, } \\
\text { penicillamine, and sulfasalazine }\end{array}$ \\
\hline $\begin{array}{l}\text { Eosinophilic } \\
\text { pneumonia }\end{array}$ & $\begin{array}{l}\text { Nonsteroidal anti-inflammatory drugs, } \\
\text { penicillamine, and sulfasalazine }\end{array}$ \\
\hline
\end{tabular}

have a satisfactory prognosis. On the contrary, failure to identify DI-ILD may significantly increase patient morbidity and mortality. ${ }^{43}$

Clinical and radiological findings of DI-ILD are nonspecific and usually mimic those of opportunistic infections or of exacerbation of CTD-related lung disease. Bronchoalveolar lavage may aid in the differential diagnosis of these entities. ${ }^{32,43}$

Methotrexate is considered to be the drug with more potential to cause DI-ILD among all the medications used to treat patients with CTDs. ${ }^{2}$ Patients usually become symptomatic months after starting the treatment. The most common manifestations of methotrexate-induced lung disease are NSIP and hypersensitivity-like reactions resembling hypersensitivity pneumonitis (Fig 17). ${ }^{44,45}$ Toxicity to cyclophosphamide may occur between 2 weeks and 13 years after drug administration and usually presents as diffuse alveolar damage, NSIP, or OP. Both methotrexate- and cyclophosphamide-induced lung toxicities

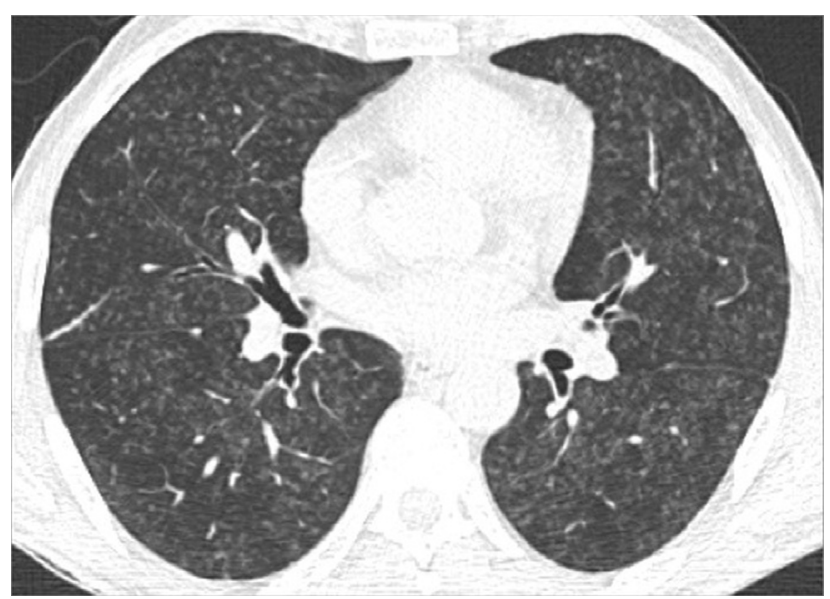

FIG 17. Hypersensitivity reaction in a 60-year-old man with RA undergoing treatment with methotrexate. HRCT scan shows diffuse poorly defined centrilobular ground-glass nodules. show no evident relationship with dose and duration of therapy and are associated with satisfactory prognosis after drug withdrawal. ${ }^{45}$ Association between $\mathrm{TNF} \alpha$ antagonists and new-onset or exacerbation of ILD is also described in the literature. ${ }^{46}$

\section{Opportunistic Infections}

Patients with CTDs have increased risk of developing pulmonary infections. Although intrinsic immunologic abnormalities predispose the patient to nonspecific infections (such as community-acquired pneumonia in SLE and aspiration pneumonia in SSc), severe immunosuppression related to several therapeutic agents (e.g., corticosteroids, methotrexate, and cyclophosphamide) might lead to atypical or more severe pulmonary and systemic infections. ${ }^{47}$ As such, patients with SLE under immunosuppressive treatment may present infections to mycobacteria (Fig 18), Pneumocystis jirovecii, cytomegalovirus, Aspergillus species, and Nocardia. ${ }^{1,23}$ Likewise, patients with RA, especially
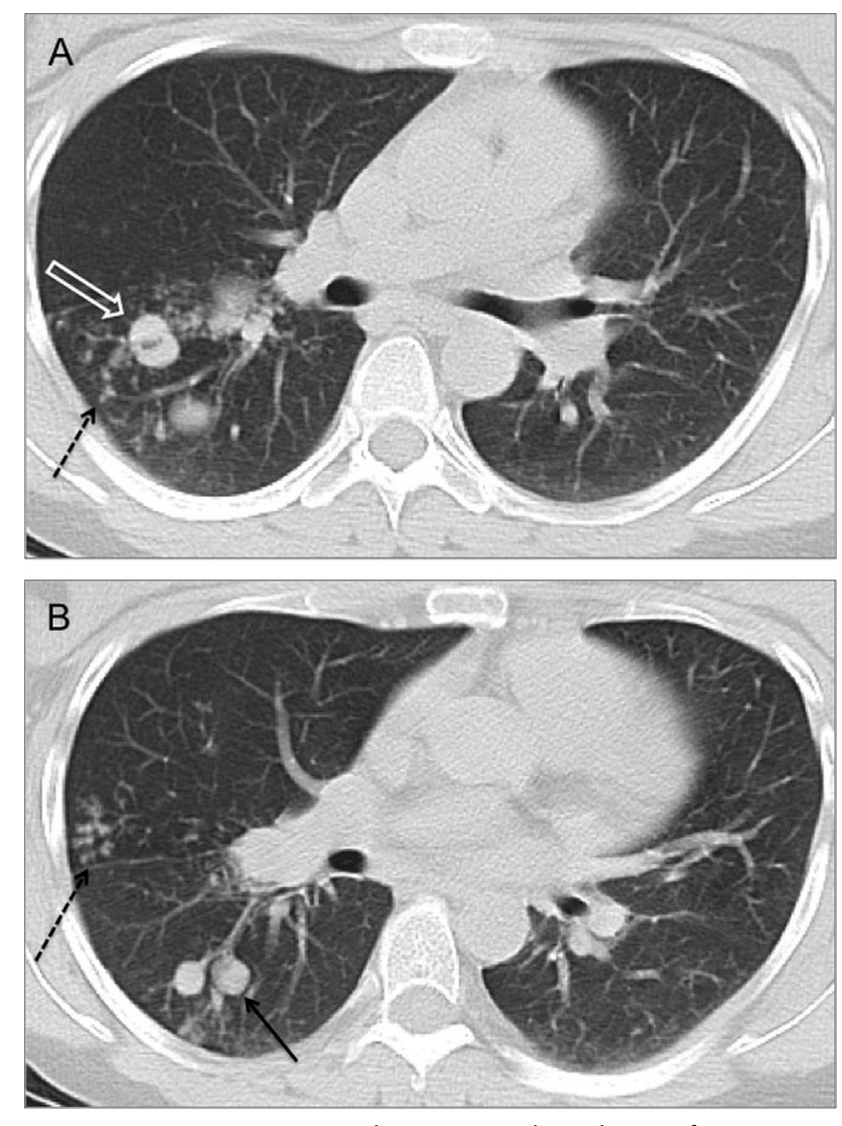

FIG 18. Postprimary Mycobacterium tuberculosis infection in a 36-year-old woman with SLE under corticosteroid therapy. HRCT images show nodules (arrow in (B)), some of which undergoing cavitation (open arrow in (A)), and centrilobular micronodules (dashed arrows) representing endobronchial dissemination of tuberculosis. 

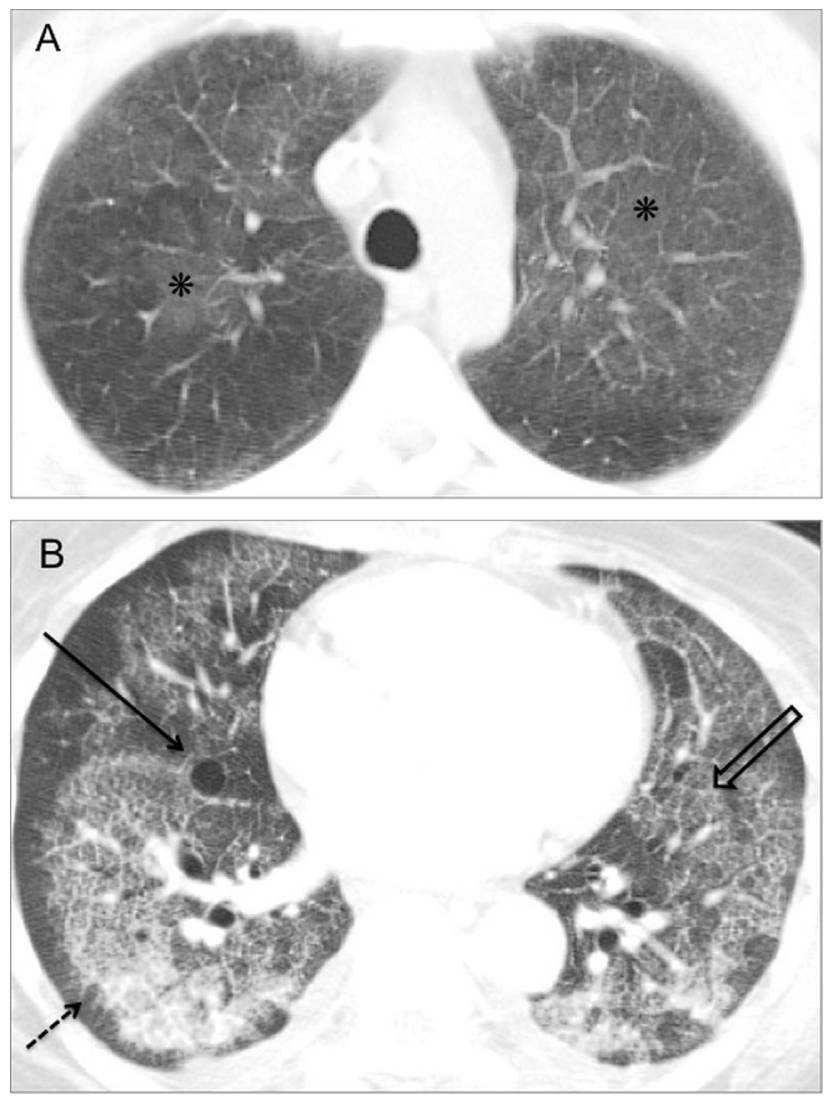

FIG 19. Pneumocystis jirovecii pneumonia in 2 patients with CTDs under immunosuppressive treatment. HRCT scans show bilateral diffuse ground-grass opacities (* in (A)), septal thickening (open arrow in $(B))$, and a pneumatocele (arrow in (B)). The peripheral lung is spared (dashed arrow in (B)).

those under treatment with TNF $\alpha$ inhibitors, are susceptible to opportunistic microorganisms such as Mycobacterium tuberculosis, Listeria monocytogenes, and $P$. jirovecii. ${ }^{35}$ As treatment with high doses of corticosteroids or immunosuppressive drugs is associated with reactivation of latent tuberculosis, regular screening is recommended in countries where tuberculosis is endemic. ${ }^{1}$

The prevalence of $P$. jirovecii pneumonia in patients with CTDs is reported to be approximately $1 \%-2 \%$, occurring most commonly among those receiving immunosuppressive therapy. ${ }^{48}$ This diagnosis should be considered when bilateral perihilar ground-grass opacities, interstitial thickening, or both, are seen in HRCT studies of this group of patients (Fig 19). ${ }^{9}$ However, exacerbations of CTD-related lung disease and drug-induced lung toxicity (specifically subacute hypersensitivity pneumonitis to methotrexate) may present similar clinical and radiological manifestations as $P$. jirovecii pneumonia. ${ }^{49}$

\section{Conclusions}

The thoracic organs are frequent targets of immunemediated injury in CTDs. Any thoracic compartment can be affected; however, the most important manifestations are ILD and PAH. Though challenging, the radiologist's role is to recognize the most common patterns of lung involvement in patients with CTDs, assess treatment efficacy, and evaluate treatmentrelated complications, namely drug toxicity and opportunistic infections. As such, general knowledge of the broad spectrum of HRCT features associated with each CTD is paramount.

\section{REFERENCES}

1. Capobianco J, Grimberg A, Thompson B, et al. Thoracic manifestations of collagen vascular diseases. Radiographics 2012;32:33-50.

2. Olson A, Brown K, Fischer A. Connective tissue diseaseassociated lung disease. Immunol Allergy Clin North Am 2012;32:513-36.

3. Vij R, Strek M. Diagnosis and treatment of connective tissue disease-associated interstitial lung disease. Chest 2013;143 (3):814-24.

4. Bryson T, Sundaram B, Khanna D, et al. Connective tissue disease-associated interstitial pneumonia and idiopathic interstitial pneumonia: Similarity and difference. Semin Ultrasound CT MR 2014;35(1):29-38.

5. Franquet T. High-resolution CT of lung disease related to collagen vascular disease. Radiol Clin North Am 2001;39 (6):1171-87.

6. Mueller-Mang C, Grosse C, Schmid K, et al. What every radiologist should know about idiopathic interstitial pneumonias. Radiographics 2007;27:595-615.

7. Kim E, Lee K, Johkoh T, et al. Interstitial lung diseases associated with vascular diseases: Radiologic and histopathologic findings. Radiographics 2002;22:S151-65.

8. Cottin V. Significance of connective tissue diseases features in pulmonary fibrosis. Eur Respir Rev 2013;22(129):273-80.

9. Silva CI, Müller NL. Interstitial lung disease in the setting of collagen vascular disease. Semin Roentgenol 2010;45(1): 22-8.

10. Mittoo S, Gelber AC, Christopher-Stine L, et al. Ascertainment of collagen vascular disease in patients presenting with interstitial lung disease. Respir Med 2009;103(8):1152-8.

11. Travis WD, Matsui K, Moss J, et al. Idiopathic nonspecific interstitial pneumonia: Prognostic significance of cellular and fibrosing patterns: Survival comparison with usual interstitial pneumonia and desquamative interstitial pneumonia. Am J Surg Pathol 2000;24:19-33.

12. Raghu G, Collard HR, Egan JJ, et al. An official ATS/ERS/ JRS/ALAT statement: Idiopathic pulmonary fibrosis: Evidencebased guidelines for diagnosis and management. Am J Respir Crit Care Med 2011;183(6):788-824.

13. Lynch DA, Huckleberry JM. Usual interstitial pneumonia: Typical and atypical high-resolution computed tomography features. Semin Ultrasound CT MR 2014;35(1):12-23. 
14. Johkoh T. Nonspecific interstitial pneumonia and usual interstitial pneumonia: Is differentiation possible by highresolution computed tomography? Semin Ultrasound CT MR 2014;35(1):24-8.

15. Ujita M, Renzoni EA, Veeraraghavan S, et al. Organizing pneumonia: Perilobular pattern at thin-section CT. Radiology 2004;232(3):757-61.

16. Hansell DM, Bankier AA, MacMahon H, et al. Fleischner Society: Glossary of terms for thoracic imaging. Radiology 2008;246(3):697-722.

17. Swigris JJ, Berry GJ, Raffin TA, et al. Lymphoid interstitial pneumonia: A narrative review. Chest 2002;122(6):2150-64.

18. Carrillo J, Restrepo CS, Rosado de Christenson M, et al. Lymphoproliferative lung disorders: A radiologic-pathologic overview. Part I: Reactive disorders. Semin Ultrasound CT MR 2013;34(6):525-34.

19. Peña E, Dennie C, Veinot J, et al. Pulmonary hypertension: How the radiologist can help. Radiographics 2012;32(1):9-32.

20. Grosse C, Grosse A. CT findings in diseases associated with pulmonary hypertension: A current review. Radiographics 2010;30(7):1753-77.

21. Mayberry JP, Primack SL, Müller NL. Thoracic manifestations of systemic autoimmune diseases: Radiographic and high-resolution CT findings. Radiographics 2000;20(6): 1623-35.

22. Madani G, Katz RD, Haddock JA, et al. The role of radiology in the management of systemic sclerosis. Clin Radiol 2008; 63(9):959-67.

23. Crestani B. The respiratory system in connective tissue disorders. Allergy 2005;60(6):715-34.

24. Moore OA, Goh N, Corte T, et al. Extent of disease on highresolution computed tomography lung is a predictor of decline and mortality in systemic sclerosis-related interstitial lung disease. Rheumatology 2013;52(1):155-60.

25. Desai SR, Veeraraghavan S, Hansell DM, et al. CT features of lung disease in patients with systemic sclerosis: Comparison with idiopathic pulmonary fibrosis and nonspecific interstitial pneumonia. Radiology 2004;232(2):560-7.

26. Strollo D, Goldin J. Imaging lung disease in systemic sclerosis. Curr Rheumatol Rep 2010;12(2):156-61.

27. Kang J, Litmanovich D, Bankier AA, et al. Manifestations of systemic diseases on thoracic imaging. Curr Probl Diagn Radiol 2010;39(6):247-61.

28. Bouros D, Pneumatikos I, Tzouvelekis A. Pleural involvement in systemic autoimmune disorders. Respiration 2008;75(4): 361-71.

29. Goh YP, Naidoo P, Ngian GS. Imaging of systemic lupus erythematosus. Part I: CNS, cardiovascular, and thoracic manifestations. Clin Radiol 2013;68(2):181-91.

30. Gheita TA, Azkalany GS, El-Fishawy HS, et al. Shrinking lung syndrome in systemic lupus erythematosus patients; clinical characteristics, disease activity and damage. Int $\mathrm{J}$ Rheum Dis 2011;14(4):361-8.

31. Schreiber BE, Connolly MJ, Coghlan JG. Pulmonary hypertension in systemic lupus erythematosus. Best Pract Res Clin Rheumatol 2013;27(3):425-34.
32. Massey H, Darby M, Edey A. Thoracic complications of rheumatoid disease. Clin Radiol 2013;68(3):293-301.

33. Kim EJ, Elicker BM, Maldonado F, et al. Usual interstitial pneumonia in rheumatoid arthritis-associated interstitial lung disease. Eur Respir J 2010;35:1322-8.

34. Webb R, Higgins C. Thoracic Imaging: Pulmonary and Cardiovascular Radiology. Philadelphia: Lippincott Williams \& Wilkins, 2005.

35. Manjunatha YC, Seith A, Kandpal H, et al. Rheumatoid arthritis: Spectrum of computed tomographic findings in pulmonary diseases. Curr Probl Diagn Radiol 2010;39(6): 235-46.

36. Matsuyama N, Ashizawa K, Okimoto T, et al. Pulmonary lesions associated with Sjögren's syndrome: Radiographic and CT findings. Br J Radiol 2003;76(912):880-4.

37. Parambil JG, Myers JL, Lindell RM, et al. Interstitial lung disease in primary Sjögren syndrome. Chest 2006;130(5): 1489-95.

38. Taouli B, Brauner MW, Mourey I, et al. Thin-section chest CT findings of primary Sjögren's syndrome: Correlation with pulmonary function. Eur Radiol 2002;12(6):1504-11.

39. Marie I, Hatron PY, Dominique S, et al. Short-term and longterm outcomes of interstitial lung disease in polymyositis and dermatomyositis: A series of 107 patients. Arthritis Rheum 2011;63(11):3439-47.

40. Kanne JP, Yandow DR, Haemel AK, et al. Beyond skin deep: Thoracic manifestations of systemic disorders affecting the skin. Radiographics 2011;31(6):1651-68.

41. Tansey D, Wells AU, Colby TV, et al. Variations in histological patterns of interstitial pneumonia between connective tissue disorders and their relationship to prognosis. Histopathology 2004;44(6):585-96.

42. Bodolay E, Szekanecz Z, Dévényi K, et al. Evaluation of interstitial lung disease in mixed connective tissue disease (MCTD). Rheumatology 2005;44(5):656-61.

43. Schwaiblmair M, Behr W, Haeckel T, et al. Drug induced interstitial lung disease. Open Respir Med J 2012;6:63-74.

44. Ellis SJ, Cleverley JR, Müller NL. Drug-induced lung disease: High-resolution CT findings. Am J Roentgenol 2000;175 (4):1019-24.

45. Rossi SE, Erasmus JJ, McAdams HP, et al. Pulmonary drug toxicity: Radiologic and pathologic manifestations. Radiographics 2000;20(5):1245-59.

46. Roubille C, Haraoui B. Interstitial lung diseases induced or exacerbated by DMARDS and biologic agents in rheumatoid arthritis: A systematic literature review. Semin Arthritis Rheum 2014;43(5):613-26.

47. Hamilton CD. Immunosuppression related to collagenvascular disease or its treatment. Proc Am Thorac Soc 2005;2: 456-60.

48. Sepkowitz KA. Opportunistic infections in patients with and patients without acquired immunodeficiency syndrome. Clin Infect Dis 2002;34(8):1098-107.

49. Ikkuni N, Kitahama M, Ohta S, et al. Evaluation of pneumocystis pneumonia infection risk factors in patients with connective tissue disease. Mod Rheumatol 2006;16(5):282-8. 